\title{
PHENOMENOLOGICAL MODEL FOR DETERMINING VELOCITY FIELD OF LPG JET IN COMBUSTION CHAMBER OF DIRECT INJECTION S.I. ENGINE
}

\author{
Bui Van Ga, Phung Xuan Tho, \\ Nhan Hong Quang, NGuYen HuU Huong \\ University of Danang
}

\begin{abstract}
A phenomenological model has been established to predict the velocity distribution of LPG (Liquefied Petroleum Gas) jet in combustion chamber of spark ignition (SI) engine. A shaped coefficient $\beta$ governing the similarity of velocity profiles of LPG jets has been defined based on the theoretical and experimental analyses of turbulent diffusion jets. The results show that $\beta$ is constant for steady jet but it is not the case for unsteady one. The model will enable us to calculate the velocity profiles of LPG jet after ending injection. This is necessary for research of stratified combustion in direct injection LPG SI engines.
\end{abstract}

\section{Introduction}

Up to now, the models describing the evolution of a fuel jet inside a combustion chamber were often based on a stable and steady jet. This is good suitability for Diesel engine where the diffusion combustion occurs during injection. The direct injection spark ignition engines (GDI engine) is different from Diesel engine because the injection process ends before ignition occurs. It is different also from traditional gasoline engine because the mixture is not homogeny in regime of stratified combustion [5]. So in case of GDI engine, the evolution of jet after ending injection is particularly important with respect to the operating ability [6].

Detailed analyses of the velocity field of turbulent diffusion jet were performed using specific multi-dimensional codes, for example KIVA, FIRES [2].... For purpose of simplicity, one-dimensional models have been established to describe the development of fuel jet in the air or in the combustion chamber of engine [8], [10]. In the later models, the variation of scalar $\phi$ on jet axis is calculated by integral equations system whereas its radical distribution is determined by similarity law:

$$
\Phi(x, y)=\Phi_{m}(x) \cdot f(\eta) .
$$

The similarity function $f(\eta)$ can be arbitrarily experimentally assumed. In the turbulent diffusion jet model based on the "top-hat profile" assumption [4], the following Gaussian similarity rule was used by Cook:

$$
f(\eta)=\exp \left(-\ln (2) \cdot \eta^{2}\right)
$$

where $\eta=r / r_{0,5}, r_{0,5}$ is the distance from axis of jet to the point where its velocity is equal to a half of the maximum velocity at the given cross section. 
Otherwise, the similarity function can be also derived from the analytic studies of turbulent diffusion jet theory. Basing on the assumption of boundary layer approximation and expressing turbulent eddy viscosity via the Prandtl mixing length, Come-Bellot [3] found the similarity function $f(\eta)$ for a two-dimensional jet:

$$
f(\eta)=\frac{1}{\operatorname{ch}^{2}(k \eta)} .
$$

The function $f(\eta)$ has a significant effect on accuracy in calculating turbulent jet using one-dimensional models. In the present paper, the function $f(\eta)$ will be defined for an axisymmetrical LPG jet in combustion chamber of direct injection spark ignition engine.

\section{Theory of similarity function $f(\eta)$}

We consider a jet of incompressible fuel issuing from a nozzle into the quiescent air with constant pressure. The velocity field is governed by the system of Navier Stokes equation and continuity one written in cylindrical coordinates. Using the boundary layer assumption, the quantity variations along the radical direction are neglected as comparing to their variations along the axial direction, the system can be written as:

$$
\begin{aligned}
\bar{U} \frac{\partial \bar{U}}{\partial x}+\bar{V} \frac{\partial \bar{U}}{\partial r} & =-\frac{1}{r}\left[\frac{\partial}{\partial r}(r \overline{u v})\right], \\
\frac{\partial \bar{U}}{\partial x} & =-\frac{1}{r}\left(\frac{\partial r \bar{V}}{\partial r}\right) .
\end{aligned}
$$

In above equations, the conventional Reynolds decomposition is applied [3]:

$$
U_{i}=\bar{U}_{i}+u_{i} .
$$

Based on similarity assumption we can express the mean velocity at an arbitrary point $(x, r)$ in jet as follows:

$$
\bar{U}(x, r)=U_{m}(x) f(\eta),
$$

where

$$
\eta=\frac{r}{\delta(x)} .
$$

Solving equation system (2.1) with help of 'Prandtl mixing length' assumption, we obtain:

$$
\delta(x) \sim x \quad \text { and } \quad U_{m}(x) \sim \frac{1}{x}
$$

for full developed jet (outside the transition region which is closed to the jet nozzle). The similarity function of the velocity field $f(\eta)$ takes the form:

$$
f(\eta)=\left(1-k \eta^{3 / 2}\right),
$$


$f(\eta)$ takes the value within $[0,1]$. If $\delta=b$ (width of jet) is chosen then $\eta$ is defined within $[0,1]$. With boundary condition, $f(0)=1$ and $f(1)=0$, we obtain $k=1$. The function $f(\eta)$ is then writen as:

$$
f(\eta)=\left(1-\eta^{3 / 2}\right)
$$

For instationary jet developing in combustion chamber with small length scale, in considering $U_{m}(x) \sim 1 / x$ and the boundary condition $U_{m}(0)=U_{j}, U_{m}(\infty)=0$, we can suggest an experimental expresion of $U_{m}(x)$ in the form:

$$
U_{m}(x)=\frac{U_{j}}{\beta x+1}
$$

where $\beta$ is the shaped coefficient of velocity profiles. We have finally the expression for velocity profile:

$$
\bar{U}(x, r)=\frac{U_{j}}{\beta x+1}\left(1-\left(\frac{r}{b}\right)^{3 / 2}\right) .
$$

The present paper will focus on determination of coefficient $\beta$ for LPG jet in combustion chamber of SI engine.

\section{Experimental model of LPG jet shaped}

The schema of jet development in combustion chamber during and after ending injection can be presented in Fig. 1. Theoretical and empirical studies enable us to determine the penetration of the jet during the injection process leading to the following general expression [1]:

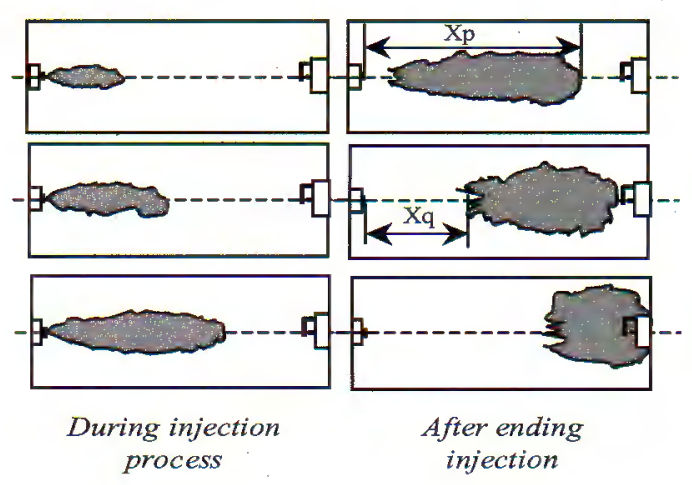

Fig. 1. Schema of jet evolution

$$
X_{p}=a \sqrt{U_{e q} d_{e q} t}
$$

where

$$
d_{e q}=d \sqrt{\frac{\rho_{f}}{\rho_{a}}} \text { and } U_{e q}=\sqrt{\frac{1}{t} \int_{0}^{t} U^{2}(\tau) d \tau} .
$$

$U(\tau)$ is instantaneous injection velocity.

In these above expressions, the origin of time coordinates is chosen as the moment at starting injection, $a$ is the penetration coefficient, which depends on the type of using 
nozzles only and takes the variable value from 2.4 to 3.0 for the traditional liquid fuel [1]. The above-mentioned penetrating law is found independent on the viscosity of fuel and air as well as on jet properties (one or two phases) and the diameter of the fuel drop.

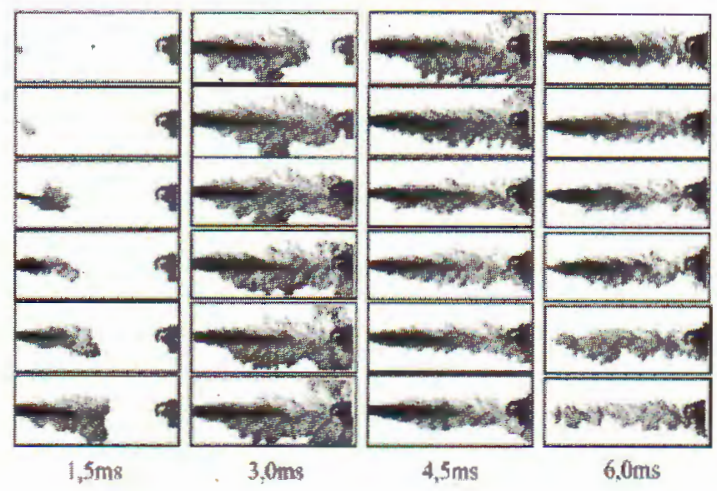

Fig. 2. The evolution of LPG jet in the combustion chamber $\left(m_{f}=1.094 \mathrm{~kg} / \mathrm{h}\right)$

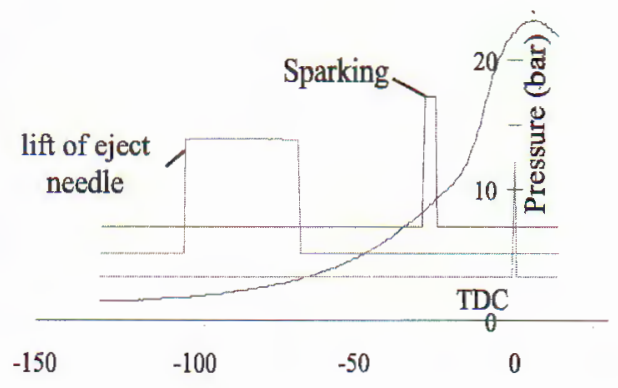

Fig. 3. Variation of pressure in combustion chamber $\left(m_{f}=1.094 \mathrm{~kg} / \mathrm{h}\right)$

After ending injection, the tip-part of the spray continue to penetrate to the space of combustion chamber and its tail-part gradually separates from the nozzle. Penetration of the spray tail-part is calculated by the same expression as being applied to that of the spray tip-part [1]:

$$
X_{q}=a^{\prime} \sqrt{U_{e q} d_{e q}\left(t-\Delta_{i n j}\right)},
$$

coefficient $a^{\prime}$ is approximately $a / 2$.

Thus, the penetration of spray depends on the empirical coefficient a tabulated for different types of using fuels. In this paper, the empirical coefficient a is defined for LPG jets. Fig. 2 illustrates the evolution of the LPG jet in the combustion chamber of the experimental engine and the pressure curve in combustion chamber as a function of time is presented in Fig. 3. The details of experimental apparatus can be found in [7]. The LPG fuel mixture consisted of $50 \%$ propane and $50 \%$ butane, therefore its mean density

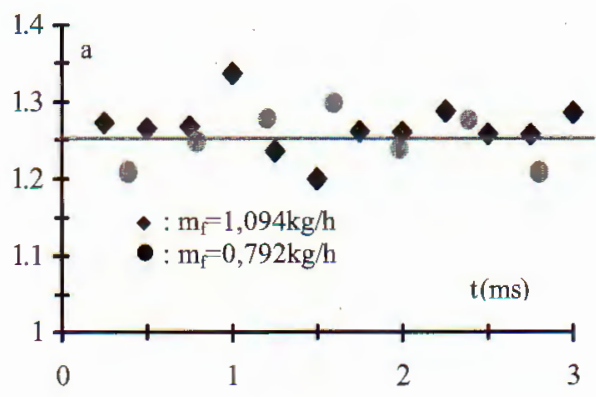

Fig. 4. Variation of the coefficient $a$ for the LPG jet in combustion chamber is $\rho_{f}=520 \mathrm{~kg} / \mathrm{m}^{3}$. Nozzle diameter $d=$ $0.3 \mathrm{~mm}$ and mass flow rate $1.094 \mathrm{~kg} / \mathrm{h}$ were used. The injection duration is $6 \mathrm{~ms}$. The engine operates at the regime $n=1010 \mathrm{rpm}$ (rounds per minute). Since the lift of the eject needle is kept almost invariant during the injection time (Fig. 2), the exit velocity can be considered as constant. Under the above experimental condition, the equivalent diameter of the nozzle is $d_{e q}=6.03 \mathrm{~mm}$. Experimental results shown in Fig. 4 lead to the coefficient $a$ in function (3.2) being approximately 1.25 for the LPG jet in combustion chamber of engine. 
After the end of injection, because of the fast-vaporized property of LPG we can observe only 4-5 photographs until the contrast of the space containing fuel in combustion chamber is insufficient for clear appearance on the negative films. Based on the mathematical expression prescribed to the traditional fuel jet, we can predict the movement of fuel jet tail-part after ending injection as given by expression (3.3).

Fig. 5 presents the movements of the tip-part and the tail-part of the LPG fuel jet during injection and after ending injection. The mass flow rate of the jet is $m_{f}=1.094 \mathrm{~kg} / \mathrm{h}$ and injection duration is $1.5 \mathrm{~ms}$. As soon as the injection ends, thanks to kinetic energy, the cloud of fuel continues to penetrate to the space of combustion chamber with a gradually decrease in velocity because of the entrained air flow (momentum conservation law). The gradually disappearance of the jet tail-part also bears a significance as the rich-fuel region disappears step-by-step and only the leaner-fuel exterior region of jet is left. The concentration distribution in spray only remains as long as the jet kinetic energy is still enabled to move fuel. Then, fuel will self-scatter to the air in the combustion chamber conforming to the natural diffusion law and will be uncontrolled by jet movement. Therefore, definition of the exact time to spark is very important when the engine operates in stratified combustion regime.

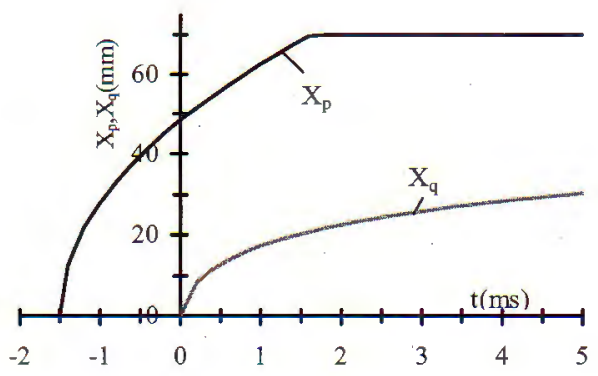

Fig. 5. Movement of the tip-part and tail-part of the spray as a fuction of time after ending injection process

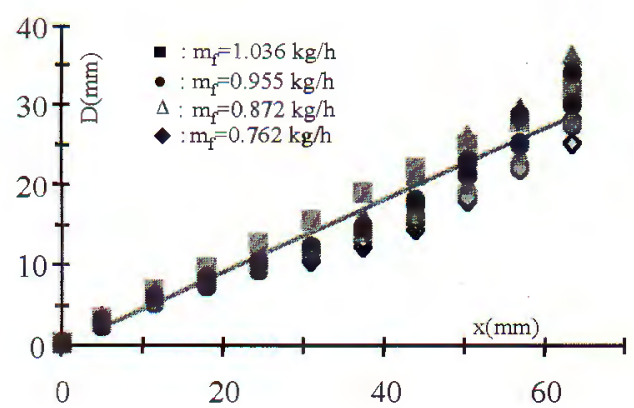

Fig. 6. Variance of sparay diameter $D$ versus the distance from the jet nozzle $x$

The development of jet width as a function of the distance from the nozzle for different injection regimes determined by theoretical analysis (2.5) is shown in Fig. 6. This proposes that their mean line takes a value of 0.45 in its slope. The width evolution of LPG jet in combustion chamber is therefore written as:

$$
b=0.225 x \text {. }
$$

\section{Phenomenological model for velocity field of LPG jet}

Penetration and width of jet are necessary for calculating physical fields. As presented above, the velocity profile has relationship to the shaped coefficient $\beta$. This coefficient can be calculated using the kinetic energy-balanced equation of the whole jet. If we neglect 
energy losses due to mixing, the kinetic energy total of the injected fuel mass will be equal to the kinetic energy yielded by the movement of all of gaseous elements within the jet. Assuming that the exit velocity $U_{j}$ is invariant and $M_{f}$ denotes the total of fuel injected into combustion chamber, we have:

$$
\pi \int_{x_{q}}^{x_{p}} \int_{0}^{b} \rho U^{2} r d r d x=\frac{1}{2} M_{f} U_{j}^{2}
$$

Inserting the expression of $U(x, r)(2.9)$ into (4.1), we have:

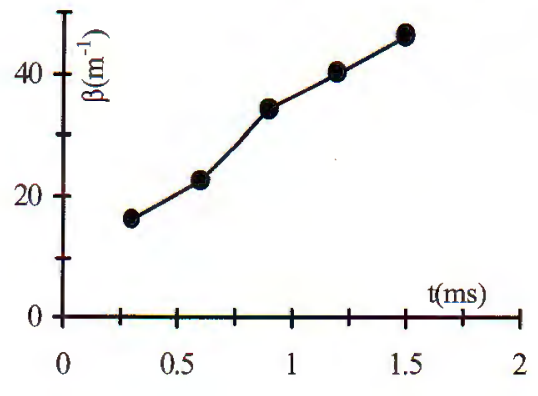

Fig. 7. Variation of $\beta$ as a funtion of time after ending injection

$$
\pi \int_{x_{q}}^{x_{p}} \frac{1}{(\beta x+1)^{2}} \int_{0}^{b} \rho\left[1-\left(\frac{r}{b}\right) \frac{3}{2}\right]^{2} r d r d x=\frac{1}{2} M_{f}
$$

At an arbitrary point of time, the values of $X_{q}, X_{p}, b$ are defined by (3.1), (3.3) and (3.4), fuel mass $M_{f}$ is known, the equation (4.2) contains uniquely the unknown $\beta$. This equation can be solved by Newton's method.

Fig. 7 shows the variation of coefficient $\beta$ as a function of time after ending injection given by equation (4.2). The injected fuel mass is $7 \mathrm{mg}$ during injection time of $3 \mathrm{~ms}$. We observe that $\beta$ gradually increases with respect to the time. When the jet moves gradually far from the nozzle its width is expanded correlatively, the higher velocity profiles begin to disappear and the velocity gradient among parts of jet decreases also. Therefore, the process of mixing fuel and air occurs at the same high speed as that in the beginning stage when the injected process has just ended.

Since the vaporized velocity of the fuel LPG jet is much faster than that of the traditional liquid fuel jet, just after exiting nozzle the jet diameter becomes much larger than the nozzle diameter. That definitely manifests itself on the photos taking the evolution of jet in combustion chamber (Fig. 2). To describe this phenomenon, instead of the real nozzle diameter we used here the definition of equivalent diameter in expression (3.2). With this additional knowledge, the jet considered can be interpreted as a full-gaseous jet with an invariance in flow rate but with a strong decrease in exit velocity. Fig. 8 and Fig. 9 show the computational results of the velocity distributions of an LPG jet with the same injection mass of $7 \mathrm{mg}$ and the injection duration of $3 \mathrm{~ms}$. In the first case, the tip of the jet passes a distance of $60 \mathrm{~mm}$ during the injection time, whereas in the second case, the distance is $70 \mathrm{~mm}$. The value of coefficient $\beta$ calculated in the first case is $16.4 \mathrm{~m}^{-1}$ and in the latter is $21.5 \mathrm{~m}^{-1}$. From the calculations above we can draw out the conclusion that with the same injected kinetic energy the value of coefficient $\beta$ will change together with the change of the jet figuration related to pressure and temperature as well as the movement of air in the combustion chamber. 


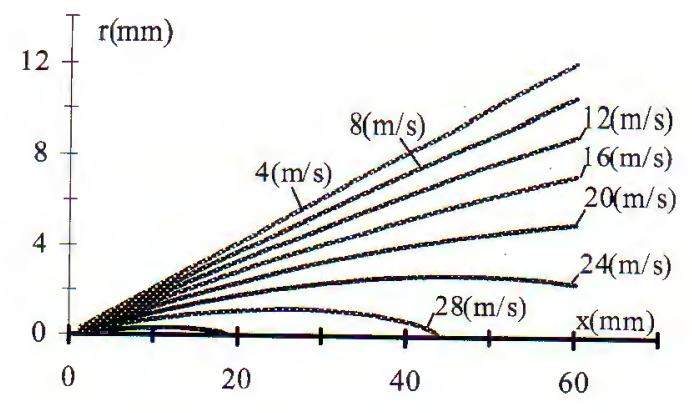

Fig. 8. Velocity field in case of the jet penetration is $60 \mathrm{~mm}$

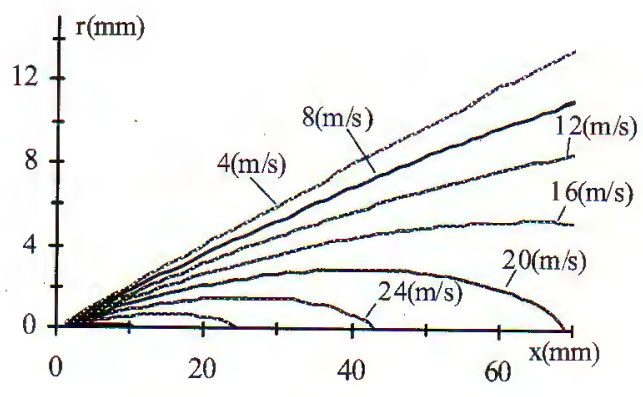

Fig. 9. Velocity field in case of the jet penetration is $70 \mathrm{~mm}$
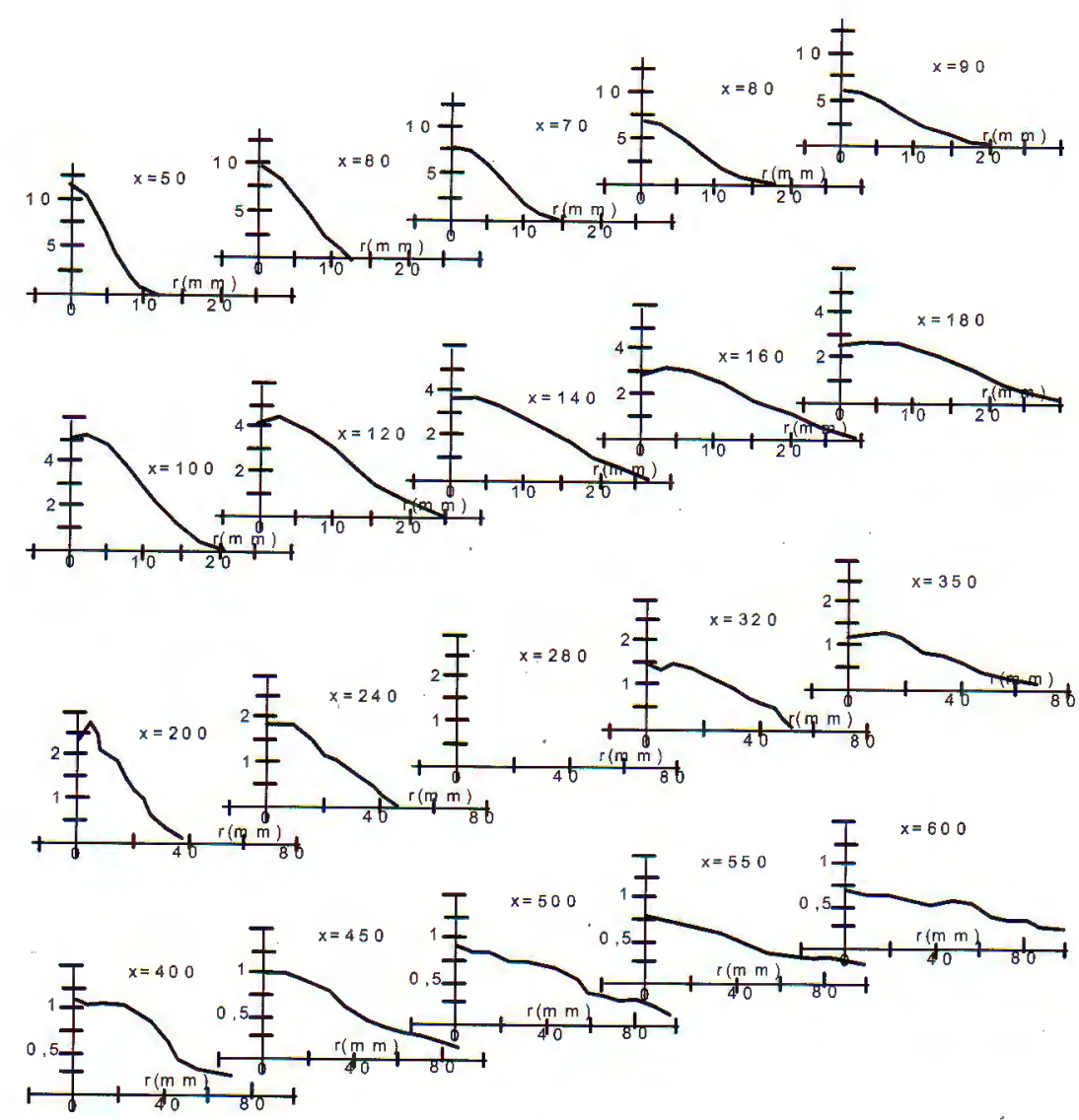

Fig. 10. The velocity profiles of a $\mathrm{CO}_{2}$ jet $\left(D_{j}=3 \mathrm{~mm}, m_{j}=1.12 \mathrm{~kg} / \mathrm{h}\right.$, vertical jet $)$ 
In view of a comparison, the measurements of jets in the atmosphere were carried out. Fig. 10 shows the velocity field of a steady $\mathrm{CO}_{2}$ vertical jet with nozzle diameter of $3 \mathrm{~mm}$ and mass flow rate of $1.12 \mathrm{~kg} / \mathrm{h}$ and Fig. 11 illustrates the measured results of the velocity distributions of an air jet with an inclination angle $30^{\circ}$ to the horizontal and mass flow rate of $1.5 \mathrm{~kg} / \mathrm{h}$. The velocity profile is measured by using Laser Doppler method that was clearly described in [10]. The result of shaped coefficient $\beta$ given by (4.2) is presented on the Fig. 12. Unlike LPG unsteady jet in combustion chamber, in case of steady jet in the atmosphere, $\beta$ can take a constant value. For $\mathrm{CO}_{2}$ and air jets in this study, the shaped coefficient $\beta$ is approximatively equal to $25 \mathrm{~m}^{-1}$.

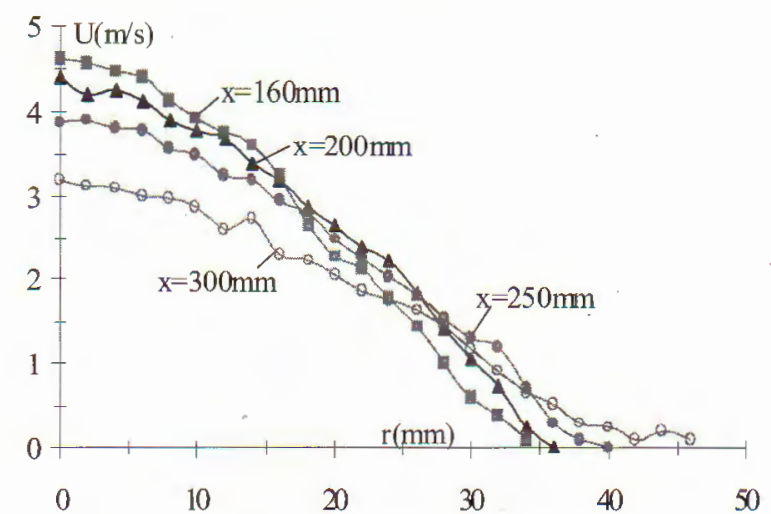

Fig. 11. The velocity profiles of a diffusion air jet $\left(d_{j}=2 \mathrm{~mm}, m_{j}=1.5 \mathrm{~kg} / \mathrm{h}, \theta=\pi / 6\right)$

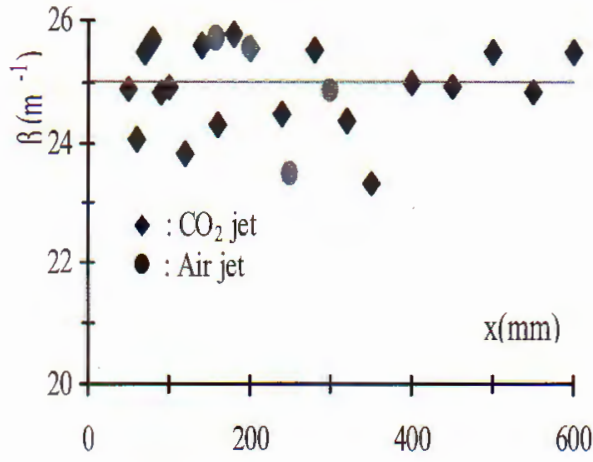

Fig. 12. The shaped coefficient of velocity profile of jet in the atmosphere

\section{Conclusion}

The empirical coefficients describing the geometric shape (penetration and width) of a LPG jet in the combustion chamber of SI engine during and after ending injection have been defined. The coefficients of LPG jet are considerably different from that of traditional fuels due to the strong vaporized property of LPG.

The shaped coefficient $\beta$ of velocity profiles in case of unsteady LPG jet in combustion chamber is variable depending on physical conditions of surrounding fluid whereas it can take a constant value for steady jet in the atmosphere.

NOMENCLATURE

\begin{tabular}{llll}
\hline$a, a^{\prime}$ & Penetration coefficient & $\beta$ & $\begin{array}{l}\text { Shaped coefficient of velocity } \\
\text { profile }\end{array}$ \\
$b$ & Jet width at considered section $(\mathrm{m})$ & $\delta$ & $\begin{array}{l}\text { Specific parameter related to the } \\
\text { width of jet }\end{array}$ \\
$d$ & Diameter $(\mathrm{m})$ & $\Delta t_{i n j}$ & Injection duration (s) \\
$f$ & Similarity function & $\eta$ & Dimensionless length \\
$\mathrm{k}$ & Coefficient & $\theta$ & Inclination angle \\
$m$ & Mass flow rate $(\mathrm{kg} / \mathrm{s})$ & $\rho$ & Density $\left(\mathrm{kg} / \mathrm{m}^{3}\right)$ \\
\hline
\end{tabular}




\begin{tabular}{|c|c|c|c|}
\hline$M$ & Total mass (kg) & Subscripts & \\
\hline$t$ & Time (s) & eq & Equivalent \\
\hline$x, r$ & $\begin{array}{l}\text { Axial and radial coordinates } \\
\text { respectively }(\mathrm{m})\end{array}$ & $a, f$ & Denote air and fuel respectively \\
\hline$U, V$ & $\begin{array}{l}\text { Instantaneous velocity components } \\
\text { in direction } x \text { and } r \text { respectively }(\mathrm{m} / \mathrm{s})\end{array}$ & $\mathrm{j}$ & Related to the nozzle \\
\hline$u_{i}$ & Fluctuation of $U_{i}(\mathrm{~m} / \mathrm{s})$ & $\mathrm{m}$ & On jet axis \\
\hline$\overline{U_{i}}$ & Mean value of $U_{i}(\mathrm{~m} / \mathrm{s})$ & $\mathrm{p}, \mathrm{q}$ & $\begin{array}{l}\text { Denote tip-part and tail-part of } \\
\text { jet respectively }\end{array}$ \\
\hline
\end{tabular}

The present research is funded by National Research Program on Fundamental Science, Contract Number 321001 "Simulation of combustion in internal combustion engines and rockets"

\section{References}

1. Haupais A., Contribution a L'etude de la Combustion Dans le Moteur Diesel, These de docteur d'Etat, universite claude bernard, Lyon, 1981

2. Amsden A., KIVA, a comprehensive model for 2-D and 3-D engine simulation, $S A E$ Trans. 94 (1985).

3. Come-Bellot, Turbulence, Ecole Centrale de Lyon, 1985.

4. Cook D. K., A one-dimensional integral model of turbulent jet diffusion, Combustion and Flame 85 (1991).

5. Lee S. M., Chae J. O., Jeong Y. S., A study on stratified charge GDI engine development-combustion analysis according to the variations of injection pressure and load, Transactions of the Korean Society of Mechanical Engineers ISSN 1226-4881 22 (9) (1998) 1317-1324.

6. Duclos J. M., Zolver M., Baritaud T., 3-D modeling of combustion for DI-SI engines, Journal Oil Es Gas Science and Technology ISSN 1294-4475 54 (2) (1999) 259-264.

7. Bui Van Ga, Duong Viet Dung, Brun M., Vignonj M., Experimental investigation of LPG jet in combustion chamber of spark ignition engine, Journal Science and Technology 29 (2001) 39-43 (in Vietnamese).

8. Bui Van Ga, Duong Viet Dung, Tran Van Nam, Simulation of liquefied petroleum gas jet in combustion chamber of spark ignition engine, Vietnamese Journal of Mechanics 24 (4) (2002) 209-218.

9. Bui Van Ga, Phung Xuan Tho, Nhan Hong Quang, Experimental study of turbulent air jet by laser doppler anemometer (LDA). ICAT 2002, Proceedings International Conference on Automotive Technology, Science and Technics publishing house. 
10. Bui Van Ga, Nhan Hong Quang and Nguyen Huu Huong, Simulation of highly vapoized fuel jet in combustion chamber of spark ignition engine, Proceedings of 7th National Conference on Mechanics 4 (2002) 112-119.

Received August 8, 2003

MÔ HİNH HIỆN TUỘNG XÁC ĐỊNH TRUÒ̀NG TỐC ĐỘ CỦA TIA PHUN LPG TRONG BUỒNG CHÁY ĐỘNG CO ĐÁNH LƯA CUÕNG BƯC PHUN TRỰC TIẾP

Mô hình hiện tượng đã được xây dựng đề tính toán sự phân bố tốc độ của tia phun LPG (khí dầu mỏ hóa lơng) trong buồng cháy động cơ đánh lửa cưỡng bức. Hệ số hình dạng $\beta$ khống chế tính đồng dạng profil tốc độ của tia phun LPG đã được xác định trên cơ sở phân tích lý thuyết và thực nghiệm tia phun rối khuếch tán. Kết quả cho thấy $\beta$ là hằng số đối với tia phun dừng nhưng giá trị của nó thay đổi đối với tia phun không dừng. Mô hình này cho phép chúng ta xác định được trường tốc độ của tia sau khi kết thúc phun. Điều này có ý nghĩa quan trọng trong nghiên cứu quá trình cháy phân lớp của động cơ đánh lừa phun LPG trực tiếp. 